\title{
Non-isothermal cure and exfoliation of tri-functional epoxy-clay nanocomposites
}

\author{
F. Shiravand, J. M. Hutchinson*, Y. Calventus \\ Centre for Research in NanoEngineering, and Departament de Màquines i Motors Tèrmics, ETSEIAT, Universitat \\ Politècnica de Catalunya, 08222 Terrassa, Barcelona, Spain
}

Received 27 November 2014; accepted in revised form 25 February 2015

\begin{abstract}
The non-isothermal cure kinetics of polymer silicate layered nanocomposites based on a tri-functional epoxy resin has been investigated by differential scanning calorimetry. From an analysis of the kinetics as a function of the clay content, it can be concluded that the non-isothermal cure reaction can be considered to consist of four different processes: the reaction of epoxy groups with the diamine curing agent; an intra-gallery homopolymerisation reaction which occurs concurrently with the epoxy-amine reaction; and two extra-gallery homopolymerisation reactions, catalysed by the onium ion of the organically modified clay and by the tertiary amines resulting from the epoxy-amine reaction. The final nanostructure displays a similar quality of exfoliation as that observed for the isothermal cure of the same nanocomposite system. This implies that the intra-gallery reaction, which is responsible for the exfoliation, is not significantly inhibited by the extra-gallery epoxy-amine cross-linking reaction.
\end{abstract}

Keywords: nanocomposites, thermosetting resins, thermal properties, exfoliation, epoxy resin

\section{Introduction}

Polymer layered silicate (PLS) nanocomposites based on thermosetting polymers, such as epoxy resin, are interesting as a new class of material. In comparison with the unreinforced epoxy resin, these nanocomposites can exhibit significant improvements in mechanical properties, such as an increase in the modulus, tensile strength and impact strength, and in thermal properties such as flame retardance. As a consequence of the enhancement in these properties, they can find increased use in a wide range of industrial areas, from adhesives to coatings, and from microelectronic applications to high performance aerospace composite systems [1-7].

The procedure for the fabrication of epoxy-clay nanocomposites is based on in-situ polymerisation. Although this procedure is apparently simple, involving the mixing of the resin, clay and curing agent and effecting a suitable cure schedule, it transpires that the nanostructure and properties of the cured nanocomposite are very much dependent on the detailed conditions of the whole fabrication procedure, which includes, for example, the method of mixing the components as well as the curing process itself $[4,6]$. The curing process, which may involve isothermal or non-isothermal (dynamic) cure schedules, or a combination or sequence of either of these, may be monitored and characterised by thermal analysis techniques, from which a number of kinetic parameters may be obtained. These parameters and other details of the cure process can be related to the nanostructure development, and hence thermal analysis is a useful tool in the study of these PLS nanocomposites [8-20].

Most of the studies of the cure reaction of epoxy PLS nanocomposites have concentrated on the iso-

\footnotetext{
${ }^{\text {*Corresponding author, e-mail: hutchinson@mmt.upc.edu }}$ (C) BME-PT
} 
thermal or non-isothermal cure of bi-functional epoxy resin systems, typically diglycidyl ether of bisphenol-A (DGEBA); for example, only reference 13 of those cited immediately above (references 8 to 20) does not use DGEBA. Considerably less attention has been paid to the isothermal and/or non-isothermal cure behaviour of PLS nanocomposites based upon high-functionality epoxy resins, though there are exceptions, such as the study of triand tetra-functional epoxy resin systems [21] and our own earlier investigations of a tri-functional epoxy resin nanocomposite system based upon triglycidyl p-amino phenol (TGAP) [22, 23]. Strangely, Becker et al. [21] found that the DGEBA resin resulted in better exfoliation than for the resins of higher functionality, which is exactly contrary to our own experience. We found that, in the isothermal cure of TGAP-based nanocomposites, two distinct reactions occurred: the first of these reactions was very rapid and could be associated with the homopolymerisation reaction of the resin within the clay galleries, while the second reaction represented the cross-linking reaction of the TGAP with the curing agent, diaminodiphenyl sulphone (DDS) [22]. These TGAP systems resulted in significantly better exfoliation of the cured nanocomposite, as observed by both small angle X-ray scattering (SAXS) and transmission electron microscopy (TEM), in comparison with earlier studies of DGEBA-based nanocomposites [16-18, 20]. We attributed this to the beneficial occurrence, in the TGAP system, of the intra-gallery reaction before the bulk cross-linking reaction, whereas the homopolymerisation reaction in the DGEBA system does not occur until after the major part of the bulk crosslinking reaction has occurred, which inhibits any further separation of the clay layers from taking place.

This earlier work was related to the isothermal cure behaviour of TGAP/hardener/clay systems. Not only were the kinetic parameters and activation energy determined for each of these two reactions, intraand extra-gallery, but also the effect of the cure temperature on the thermal properties and final nanostructure was studied [23]. It transpires that the first reaction, which takes place within the clay galleries and promotes the exfoliation of the clay, is enhanced at higher cure temperature, and hence higher isothermal cure temperatures give rise to increased exfo- liation in the cured nanocomposite. This result is in agreement with the observations of Becker et al. [21], who concluded that higher cure temperatures were found to improve clay delamination, as well as increasing the toughness and modulus in the case of both DGEBA- and TGAP-based materials. In order to further clarify the process of exfoliation in these TGAP-based systems, the goal of the present paper is to investigate the non-isothermal (dynamic) cure behaviour of the same system for comparison with the isothermal cure behaviour, to obtain the kinetic parameters and activation energy, and to analyse the quality of the final nanostructure.

\section{Experimental}

\subsection{Materials}

The epoxy resin (TGAP), with trade name Araldite MY0510 (Huntsman Advanced Materials, Huntsman Corporation, Texas 77380, USA) and an epoxy equivalent between 95-106 g/eq, the curing agent, 4,4-diamino diphenyl sulphone (DDS), with trade name Aradur 976-1 (Sigma-Aldrich Quimica SL, Madrid, Spain), and the organically modified montmorillonite (MMT), with trade name Nanomer I.30E (Nanocor Inc., Arlington Heights, IL, USA), consisting of $70-75 \mathrm{wt} \%$ montmorillonite and $25-$ $30 \mathrm{wt} \%$ octadecylamine, with a cation exchange capacity of $92 \mathrm{meq} / 100 \mathrm{~g}$, were used without further purification. First, TGAP and MMT were mixed mechanically in various proportions of MMT: 0,2 , 5 and $10 \mathrm{wt} \%$. The curing agent, DDS, was added to the resin-clay mixture in a proportion of $52 \mathrm{wt} \%$, which corresponds to a slight excess of epoxy, as is recommended by the manufacturer. Stoichiometric ratios were calculated based on the amine hydrogen equivalent weight (AHEW). The mixture was finally degassed under vacuum at room temperature.

\subsection{Calorimetry}

Small sample quantities (6-10 $\mathrm{mg}$ ) were taken from this preparation and placed in sealed aluminium pans, ready for the curing experiments that were carried out using a conventional differential scanning calorimeter (DSC), DSC821e (Mettler-Toledo AG, Schwerzenbach, Switzerland). This instrument is equipped with a robot for sample placement in the furnace, with intra-cooling for sub-ambient temperatures, and with $\mathrm{STAR}^{\mathrm{e}}$ software for data evaluation. The DSC was calibrated with indium for both 
heat flow and temperature, and the experiments were performed under a flow of dry nitrogen gas at $50 \mathrm{~mL} / \mathrm{min}$.

All the samples were cured non-isothermally from 0 to $290^{\circ} \mathrm{C}$ at different heating rates, $\beta: 2,5$ and $10^{\circ} \mathrm{C} / \mathrm{min}$. The glass transition temperature, $T_{\mathrm{g}}$, of the fully cured nanocomposite was determined from a second non-isothermal scan, from 50 to $300^{\circ} \mathrm{C}$ at $10^{\circ} \mathrm{C} / \mathrm{min}$ heating rate. It is worth pointing out that the $T_{\mathrm{g}}$ of the non-isothermally cured nanocomposites is significantly lower than that for the isothermally cured nanocomposites, as a consequence of the difference in network structure. Therefore, whereas the determination of the $T_{\mathrm{g}}$ of the isothermally cured nanocomposites required the use of a temperature modulated technique, TOPEM [24], the $T_{\mathrm{g}}$ of the non-isothermally cured samples can be measured in the conventional way from the step change in the heat flow during the second scan in the DSC.

Although isothermal cure experiments were not performed for this work, comparison is made between the isothermal and the non-isothermal cure kinetics in order to clarify the reactions involved in the nonisothermal cure. For completeness, therefore, the isothermal cure procedure is also described here. The two systems involved are TGAP/DDS without any clay, cured isothermally at $150^{\circ} \mathrm{C}$ for $4 \mathrm{~h}$, and the nanocomposite system with $5 \mathrm{wt} \%$ clay, TGAP/ $\mathrm{DDS} / \mathrm{MMT}(5 \mathrm{wt} \%)$, cured isothermally at $165^{\circ} \mathrm{C}$ for $2 \mathrm{~h}$. The procedure in each case was to heat the DSC furnace to the required isothermal temperature and then to insert the freshly prepared sample into the DSC by robot and immediately start the cure experiment. These isothermal experiments were followed by a second (non-isothermal) scan in the DSC, from 50 to $300^{\circ} \mathrm{C}$, and in TOPEM, from 100 to $290^{\circ} \mathrm{C}$, in order to determine the residual heat of reaction and the glass transition temperature of the fully cured nanocomposite, respectively.

\subsection{Nanostructure characterisation}

The final nanostructure was observed for bulk samples which had been cured in an air-circulating oven in which the temperature was increased linearly with time at a rate of $10^{\circ} \mathrm{C} / \mathrm{min}$. The nanostructural characterisation was made by SAXS and TEM. X-ray diagrams were obtained using a Bruker D8 Advanced diffractometer (Bruker Corporation, Billerica, Mass, USA), measurements being taken in a range of $2 \theta$ from 1 to $8^{\circ}$ with copper $\mathrm{K} \alpha$ radiation $(\lambda=0.1542 \mathrm{~nm})$; for this, powder samples were obtained by ball-milling (Retsch model MM 400, Retsch Gmbh, Haan, Germany) the bulk samples using $20 \mathrm{~mm}$ diameter steel balls and a frequency of $20 \mathrm{~Hz}$ for a period of 4 minutes. The TEM studies were carried out on a high resolution microscope (Jeol-2010, Jeol Ltd, Tokyo, Japan) at $200 \mathrm{kV}$ accelerating voltage with high resolution imaging and with $0.23 \mathrm{~nm}$ point resolution; for this, sections of approximately $50 \mathrm{~nm}$ thickness were cut from the bulk sample by ultra-microtomy.

\section{Kinetic analysis}

The kinetic model for the time dependence of the degree of cure, $\alpha$, for a non-isothermal curing process with a constant heating rate can be described by the following Equation (1):

$\frac{\mathrm{d} \alpha}{\mathrm{d} t}=k(T) f(\alpha)$

where $k(T)$ is the rate constant, which depends on the temperature, $T$, and $f(\alpha)$ is a function of the kinetic model. The rate constant $k(T)$ can be further expressed by the Arrhenius equation (Equation (2)):

$k(T)=A \exp \left(-\frac{E}{R T}\right)$

where $E$ is the activation energy, $A$ is the pre-exponential factor, and $R$ is the universal gas constant. In this paper, the autocatalytic model in which the initial cure rate is zero, known as the Sesták-Berggren equation, is chosen for the $f(\alpha)$ function, as shown in Equation (3):

$f(\alpha)=\alpha^{\mathrm{m}}(1-\alpha)^{\mathrm{n}}$

where $m$ and $n$ are the reaction orders.

In the DSC experiments, the heat flow, $\phi$, that is measured and which results from the curing reaction is assumed to be proportional to the rate of cure according to Equation (4):

$\phi=\left(\frac{\mathrm{d} \alpha}{\mathrm{d} t}\right) \Delta H_{\text {tot }}$

where $\Delta H_{\text {tot }}$ is the total heat of cure of the reaction, obtained from the total area under the non-isothermal cure curve.

The usual approach in the kinetic analysis is to determine the activation energy by a direct method, and subsequently to determine $\ln (A)$ and the kinetic 
parameters of the function $f(\alpha)$. There has been considerable discussion in the literature about the numerous methods for the evaluation of the kinetic parameters, and in particular of the activation energy [25]. For example, Starink [26] gives an extensive comparison of methods for the analysis of constant heating rate experiments, and concludes that so-called 'Type B' methods, such as those due to Ozawa [27] and Vyazovkin $[28,29]$, in which some approximations of the temperature integral are made, are often to be preferred to those methods (Type A), such as the Friedman isoconversional method, which make no such approximations, in particular as a consequence of uncertainty in the application of a baseline to the experimental data. Accordingly, here we adopt the most commonly used Type B method, the Kissinger method [30, 31], for the determination of the activation energy. This method is based upon the determination, as a function of the heating rate $\beta$, of the temperature, $T_{\mathrm{p}}$, at which the heat flow passes through a maximum. The approximation made here is that the degree of conversion is a constant value at this peak, independent of the heating rate, and leads to a linear relationship between $\ln \left(\beta / T_{\mathrm{p}}^{2}\right)$ and the reciprocal of $T_{\mathrm{p}}$, from which the activation energy, $E$, is obtained.

Once the activation energy has been determined, the other kinetic parameters can be obtained from the DSC curves by the method suggested by Málek [32], which involves the calculation of two functions, $y(\alpha)$ and $z(\alpha)$, defined by Equations (5) and (6) for non-isothermal cure:

$$
\begin{aligned}
& y(\alpha)=\phi \cdot \exp x=\Delta H_{\mathrm{tot}} A f(\alpha) \\
& z(\alpha)=\phi T^{2}=C f(\alpha) g(\alpha)
\end{aligned}
$$

where $x=E / R T$ is a dimensionless quantity, $C=$ $\Delta H_{\mathrm{tot}} \beta / R T$, and $g(\alpha)=\int \mathrm{d} \alpha / f(\alpha)$ between the limits of 0 and $\alpha$. The functions $y(\alpha)$ and $z(\alpha)$ are invariant with respect to the heating rate and are sensitive to small changes in the kinetic model $g(\alpha)$. In practice, the $y(\alpha)$ and $z(\alpha)$ functions are normalised between 0 and 1 for convenience.

\section{Results and discussion \\ 4.1. DSC study of the TGAP/DDS system}

As a starting point and reference with which to compare the dynamic cure behaviour of the TGAP clay nanocomposite, we begin by describing the cure kinetics of the system without clay, namely the

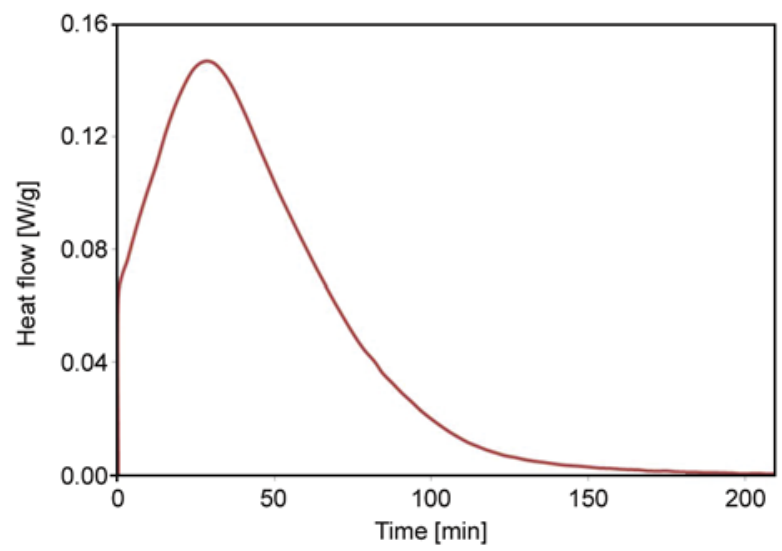

Figure 1. Isothermal DSC curve for TGAP/DDS system at $150^{\circ} \mathrm{C}$

TGAP/DDS system. In the isothermal cure of TGAP/ DDS studied earlier [24], a single exothermic peak appears, as shown in Figure 1, which is related to the cross-linking reaction of TGAP/DDS. In contrast, during a dynamic scan of the same system, as shown in Figure 2, the cure curve exhibits both a peak and a shoulder, which shift to higher temperature for faster heating rates. It is clear that the non-isothermal cure process consists of two overlapping reactions: the first is the main reaction, and is attributed to the cross-linking reaction between the TGAP and DDS; the second, which appears as a shoulder on the high temperature flank of the main peak, could be attributed to a number of different reactions, and is discussed further after examining the total heat of reaction.

The total heat of the reaction, represented by the area under both the first and second peaks, and determined as the average from the non-isothermal scans at the three different heating rates, is found to

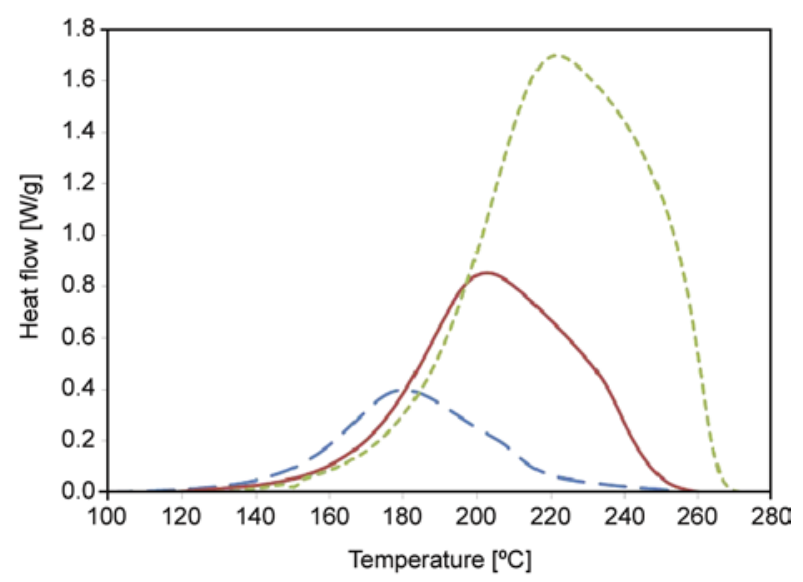

Figure 2. Non-isothermal DSC cure curve for TGAP/DDS system from $0-280^{\circ} \mathrm{C}$ with different heating rates as indicated: long dash, $2^{\circ} \mathrm{C} / \mathrm{min}$; full line, $5^{\circ} \mathrm{C} / \mathrm{min}$; short dash, $10^{\circ} \mathrm{C} / \mathrm{min}$ 
be $98.5 \mathrm{~kJ} / \mathrm{ee}$. Frigione and Calò [33] quote a range of values, from 94.6 to $96.8 \mathrm{~kJ} / \mathrm{ee}$, for the non-isothermal cure of the same TGAP epoxy with diamino diethyltoluene as the curing agent, with heating rates from 5 to $15^{\circ} \mathrm{C} / \mathrm{min}$, while Varley et al. [34] quote a value of $110.5 \mathrm{~kJ} /$ ee for the non-isothermal cure of TGAP with DDS. The result presented here, $98.5 \mathrm{~kJ} / \mathrm{ee}$, clearly lies between the values quoted by these other authors. There are several reasons why there appears to be a range of values for the heat of reaction of TGAP. Frigione and Calò [33] use an epoxy equivalent of $101 \mathrm{~g} / \mathrm{ee}$, from the manufacturer's literature, and a stoichiometric ratio of epoxy: amine, whereas Varley et al. [34] determine the epoxy equivalent by titration as $106 \mathrm{~g} / \mathrm{ee}$ and use a molar ratio epoxy:amine of 1:0.9, implying a slight excess of epoxy. Whereas previously we determined the epoxy equivalent by titration as $95 \mathrm{~g} / \mathrm{ee}$ [24], which is at the lower end of the range of values 95 to $106 \mathrm{~g} / \mathrm{ee}$ given in the manufacturer's literature, in the present work we found that some homopolymerisation of the epoxy resin had taken place, presumably initiated by the $\mathrm{N}$ in the TGAP chemical structure, resulting in a slight increase in the glass transition temperature of the resin. Accordingly, for the determination of the heat of reaction in units of $\mathrm{kJ} / \mathrm{ee}$ we also use the value of $106 \mathrm{~g} / \mathrm{ee}$ together with the molar ratio of 1:0.9 for the epoxy:amine mixture.

We discuss now the composite peak that appears in the non-isothermal scan of TGAP/DDS, which can be deconvoluted into two separate exothermic peaks by means of the PeakFit program (PF version v4, Jandel Scientific software, Systat Software Inc., San Jose, California, USA). Similar observations were made by Frigione and Calò [33], who found a pronounced shoulder in the last part of the dynamic exotherm peak, which they attributed to 'diffusional processes taking place at higher conversions', and which they were unable to fit using an autocatalytic model based upon the Equation (7) $[35,36]$ :

$\frac{\mathrm{d} \alpha}{\mathrm{d} t}=\left(k_{1}+k_{2} \alpha^{\mathrm{m}}\right)(1-\alpha)^{\mathrm{n}}$

where $k_{1}$ and $k_{2}$ represent the temperature dependent rate coefficients for the reaction catalysed by proton donors initially present in the system and those that are produced during cure, respectively. Here, the fit obtained using the asymmetric double sigmoidal function (ADL) shows quite good agree-

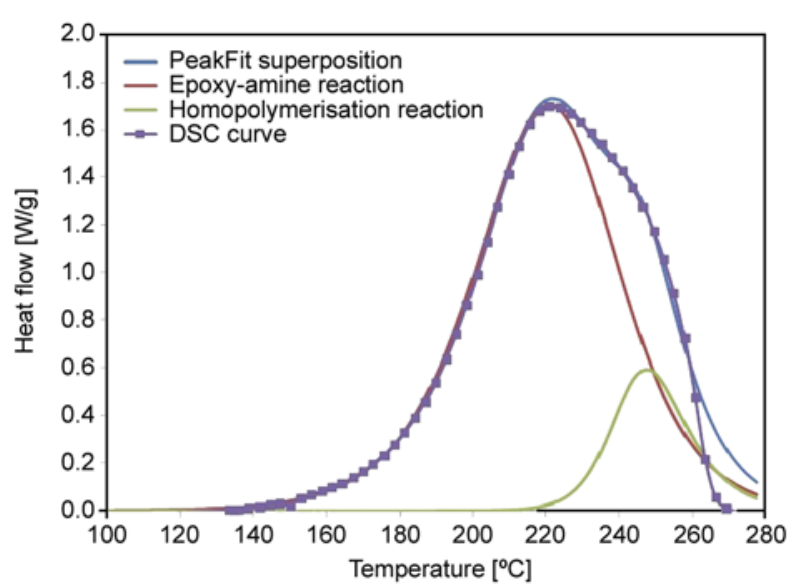

Figure 3. Deconvoluted peaks for non-isothermal cure of TGAP/DDS system at $10^{\circ} \mathrm{C} / \mathrm{min}$ : squares, original DSC curve; red curve, first reaction, epoxyamine cross-linking; green curve, second reaction, homopolymerisation; blue curve, PeakFit superposition

ment with the experimental data, a typical example being shown in Figure 3 for a heating rate of $10^{\circ} \mathrm{C} / \mathrm{min}$. It is noticeable, however, that the abrupt decrease in the experimentally measured heat flow at the end of the reaction, at temperatures higher than about $260^{\circ} \mathrm{C}$, is not well modelled by the PeakFit programme, even though the fit using the ADL function shown here was better than that obtained using any of the other available functions.

We now consider the following possibilities for the appearance of such a composite peak.

(a) The first peak is due to the reaction of the epoxy groups with primary amines, whereas the second is due to reactions with secondary amines. The argument here would be that the reactivity of primary and secondary amines is significantly different. It should be noted that DDS, particularly in respect of the secondary amines, is less reactive than other aromatic amines.

(b) For some reason the TGAP/DDS cross-linking reaction during non-isothermal cure results in a topological network structure which inhibits, at some degree of cure, the further reaction of the TGAP with the DDS. For this reason, higher temperatures are required in order to provide sufficient mobility to the reacting species, whereupon a further reaction occurs. This argument is similar to that put forward by Frigione and Calò [33], which was based upon the need for diffusional processes to take place at higher temperatures.

(c) The cure process begins with the reaction of epoxy groups with primary amines. This reac- 
tion produces secondary amines which themselves react with the epoxy to produce tertiary amines, which in turn act as an initiator of epoxy homopolymerisation. These tertiary amines act in conjunction with the nitrogen of the TGAP and the alcohol groups formed by the reaction of the TGAP with the DDS to provide a strong driving force for homopolymerisation. Possibly in combination also with topological constraints, as proposed in (b) above, this would promote epoxy homopolymerisation as the preferred reaction mechanism.

In order to distinguish between these various possibilities, some further information is required, which is afforded by the determination of the glass transition temperature of the fully cured system, $T_{\mathrm{g} o \text {. }}$. The $T_{\mathrm{g} \infty}$ for the non-isothermally cured sample of TGAP/ DDS can be determined from a second DSC scan, and the results are presented in Figure 4. As is often observed, the glass transition temperature of the sample that has been cured non-isothermally is lower than that of a sample cured isothermally, which was determined in earlier work by means of the temperature modulated DSC technique TOPEM to be around $256^{\circ} \mathrm{C}$ [24]. Here, though, the $T_{\mathrm{g}_{\infty}}$ of the nonisothermally cured system is very much lower, and decreases with increasing heating to reach a value as low as $206^{\circ} \mathrm{C}$ at $10^{\circ} \mathrm{C} / \mathrm{min}$ heating rate. This observation needs to be consistent with the possible explanation for the presence of a composite reaction curve, as shown in Figures 2 and 3, as discussed immediately above.

Possibility (a) does not present any obvious reason for why the $T_{\mathrm{g} \infty}$ should decrease with increasing heating rate, as primary and secondary amines would be expected to lead to similar network structures in the cured system. Nor does possibility (b) explain this

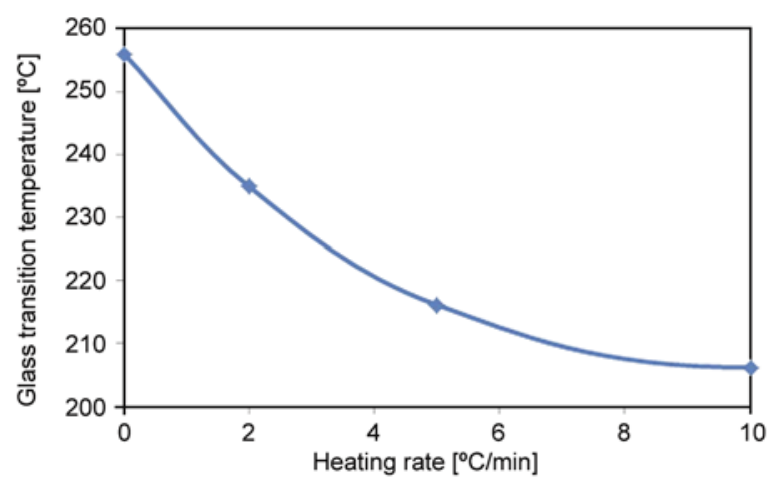

Figure 4. Glass transition temperature of the non-isothermally cured TGAP/DDS system as a function of the heating rate observation if the effect of the topological constraint is simply to delay the secondary amine reaction. On the other hand, possibility (c) implies that the network structure would indeed be different, as more homopolymerisation would occur the higher is the heating rate. The asymmetric shape of the second deconvoluted peak in Figure 3 might result from the gradually increasing contribution from the homopolymerisation reaction as the tertiary amines are progressively created. Since homopolymerisation is associated with a reduced cross-link density, and hence with a reduction in $T_{\mathrm{g} \infty}$, we believe that the second peak in the composite non-isothermal curing reaction occurs as a consequence of homopolymerisation.

We now examine the corresponding behaviour of the same system in which clay is now incorporated.

\subsection{DSC study of the TGAP/DDS/MMT system}

A typical isothermal cure curve, obtained by DSC, for the TGAP/DDS/MMT system is shown in Figure 5 , for the particular case of cure at $165^{\circ} \mathrm{C}$. As can be seen, there are clearly two exothermic peaks, distinctly different from the single exothermic reaction seen for isothermal cure of the system without clay shown in Figure 1; the first rapid peak is attributed to the TGAP homopolymerisation within the clay galleries (intra-gallery reaction), while the main broad peak is related to the cross-linking reaction between TGAP and DDS in the bulk of the sample (extra-gallery reaction). The justification for assigning the first peak to a homopolymerisation reaction catalysed by the organically modified clay has been given earlier [22, 23]. One might therefore anticipate, for the non-isothermal cure of the TGAP/DDS/MMT system, more complex reaction kinetics than has

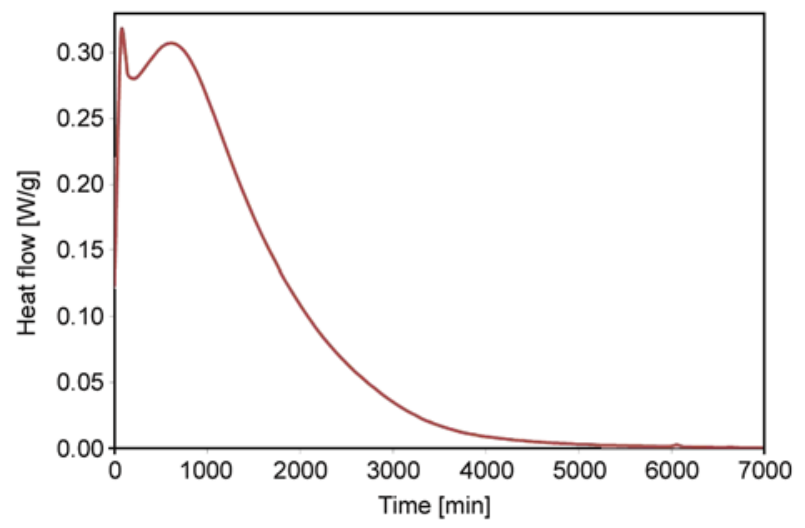

Figure 5. Isothermal DSC scan of the TGAP/DDS/ $\operatorname{MMT}(5 \mathrm{wt} \%)$ system at $165^{\circ} \mathrm{C}$ 
been shown above for the TGAP/DDS system without clay, where the TGAP/DDS reaction is accompanied by an epoxy homopolymerisation reaction catalysed by the tertiary amines. This is indeed found to be the case.

A typical non-isothermal cure curve for the TGAP/ DDS/MMT system is shown in Figure 6. Although the appearance of these curves is very similar to that of the non-isothermal cure curves for the system without clay shown in Figures 2 and 3, when they are deconvoluted by the same PeakFit program software there appear three distinctly separate peaks, rather than two, as shown in Figure 7 for the particular case of the heating rate of $10^{\circ} \mathrm{C} / \mathrm{min}$.

The assignment of the reactions associated with each of these peaks is now considered. In order to distinguish between them, the heat of reaction is determined for each deconvoluted peak, denominated $1^{\text {st }}, 2^{\text {nd }}$ and $3^{\text {rd }}$ peak in order of increasing temperature. The average values, $\Delta H_{\mathrm{av}}$, are determined from the cure curves for the three different heating rates used, for which no significant dependence of heat of reaction on heating rate was observed.

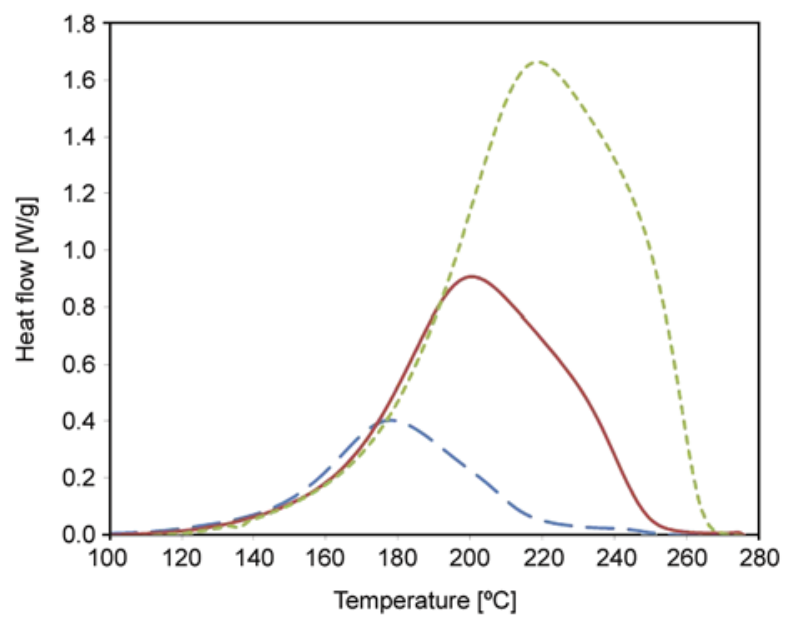

Figure 6. Non-isothermal DSC cure curve for TGAP/DDS/ MMT $(5 \mathrm{wt} \%)$ system from $0^{\circ} \mathrm{C}$ to $280^{\circ} \mathrm{C}$ for different heating rates: blue long dash, $2^{\circ} \mathrm{C} / \mathrm{min}$; red full line, $5^{\circ} \mathrm{C} / \mathrm{min}$; green short dash, $10^{\circ} \mathrm{C} / \mathrm{min}$

Table 1. Average heat of reaction, $\Delta H_{\mathrm{av}}[\mathrm{kJ} / \mathrm{ee}]$, for the total reaction and for each peak after deconvolution of the non-isothermal cure curve for the TGAP/DDS/ MMT system

\begin{tabular}{|l|c|r|r|r|}
\hline \multirow{2}{*}{ MMT content } & \multicolumn{1}{c|}{$\mathbf{0}$} & \multicolumn{1}{c|}{$\mathbf{2}$} & \multicolumn{1}{c|}{$\mathbf{5}$} & \multicolumn{1}{c|}{ [wt\%] } \\
\cline { 2 - 5 } & \multicolumn{4}{|c|}{} \\
\hline$\Delta H_{\mathrm{av}}\left(1^{\text {st }}\right.$ peak $)$ & 74.0 & 88.5 & 80.0 & 71.0 \\
\hline$\Delta H_{\mathrm{av}}\left(2^{\text {nd }}\right.$ peak $)$ & - & 6.2 & 14.0 & 19.0 \\
\hline$\Delta H_{\mathrm{av}}\left(3^{\text {rd }}\right.$ peak $)$ & 24.5 & 7.3 & 7.6 & 8.5 \\
\hline$\Delta H_{\mathrm{av}}($ total heat $)$ & 98.5 & 102.0 & 101.6 & 98.5 \\
\hline
\end{tabular}

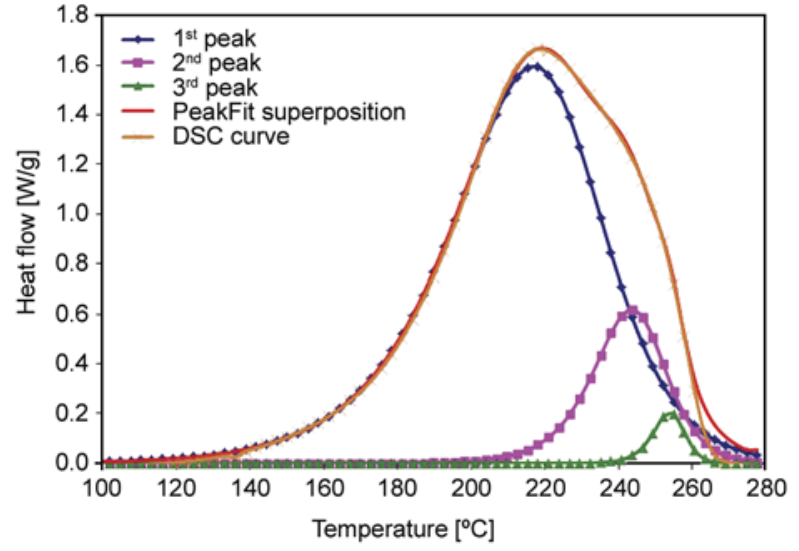

Figure 7. Deconvolution, using PeakFit program, of non-isothermal DSC scans (indicated by brown crosses) of TGAP/MMT/DDS system with $5 \mathrm{wt} \%$ MMT at $10^{\circ} \mathrm{C} / \mathrm{min}$ heating rate, into three peaks: $1^{\text {st }}$ peak, blue rhombus; $2^{\text {nd }}$ peak, cyan squares; $3^{\text {rd }}$ peak, green triangles. The full red line shows the overall fit.

The results are presented in Table 1 as a function of the MMT content, where the heats of reaction are given in units of $\mathrm{kJ} / \mathrm{ee}$ calculated using an epoxy equivalent of $106 \mathrm{~g} / \mathrm{eq}$. Each of the three peaks is now considered in turn.

The $1^{\text {st }}$ peak is clearly the most intense and occurs at the lowest temperature, with a maximum at just less than $220^{\circ} \mathrm{C}$ for the heating rate of $10^{\circ} \mathrm{C} / \mathrm{min}$, for example, and is attributed principally to the cross-linking reaction of the TGAP and the DDS. This can be justified by comparison with the system without clay, for which the $1^{\text {st }}$ peak occurred also at about $220^{\circ} \mathrm{C}$ for the same heating rate of $10^{\circ} \mathrm{C} / \mathrm{min}$, the slight reduction in the peak temperature for the system with clay being attributed to the catalytic effect of the organically modified MMT, observed earlier in epoxy-clay nanocomposites based upon DGEBA epoxy resin $[16,17]$. However, the isothermal cure for the TGAP/DDS/MMT system showed that there is a very rapid intra-gallery homopolymerisation reaction that occurs before the crosslinking reaction (see Figure 5). Furthermore, comparison of the heats of reaction given in Table 1 shows that the introduction of a small amount of clay (less than or equal to $5 \mathrm{wt} \%$ ) into the system considerably increases the heat of reaction of this $1^{\text {st }}$ peak. We believe, therefore, that this first peak includes both the cross-linking reaction and the intra-gallery homopolymerisation reaction.

It is interesting to examine further the effect of clay content on the heat of reaction of the $1^{\text {st }}$ peak. The 
heat of reaction first increases, from 74.0 to $88.5 \mathrm{~kJ} / \mathrm{ee}$ for a clay content of $2 \mathrm{wt} \%$, and thereafter decreases with increasing clay content. Such a reduction in the heat of reaction with increasing clay content (here from 2 to $10 \mathrm{wt} \%$ ) has been observed in much of our earlier work on epoxy/clay systems $[16,17,20$, 37], and can be attributed either to the effect of the stoichiometry of the reaction or to the fact that the heat of reaction for homopolymerisation is smaller than that for the epoxy-amine reaction $[17,38,39]$. The initial increase in the heat of reaction for the clay content of $2 \mathrm{wt} \%$ may be explained on the basis of stoichiometry, as follows. During the non-isothermal cure, the cross-linking reaction of the $1^{\text {st }}$ peak is accompanied by a homopolymerisation reaction, which consumes epoxy groups without any reaction with the DDS. For $0 \mathrm{wt} \%$ clay in the system TGAP/ DDS, there is a slight excess of epoxy, and hence the cross-linking reaction occurs in conditions that are not stoichiometric, for which reason the heat of reaction will be smaller than it would be in stoichiometric conditions. As the clay content is increased, the contribution of the homopolymerisation reaction increases, and consequently the cross-linking reaction associated with the 1st peak will move first into stoichiometric conditions, with a concomitant increase in the heat of reaction, and then into conditions of excess DDS, which would result in a decrease of the heat of reaction with increasing clay content. We believe that the results presented in Table 1 indicate that stoichiometric conditions for the cross-linking reaction occur when the clay content is between 0 and $5 \mathrm{wt} \%$, possibly close to $2 \mathrm{wt} \%$.

In addition to this effect, it must also be borne in mind that the heat of reaction for homopolymerisation is smaller than that for the epoxy-amine reaction $[17,38,39]$. As a consequence, there is a significant reduction in the heat of reaction as the clay content is increased beyond $2 \mathrm{wt} \%$, and in fact to such an extent that for $10 \mathrm{wt} \% \mathrm{MMT}$ the heat of reaction is even less than that for the system without clay. This result may also be taken to indicate that the amount of intra-gallery homopolymerisation that takes place is greatest for the highest clay loading; this observation will be considered later when the nanostructure of these nanocomposites is discussed. Considering now the $2^{\text {nd }}$ peak, Table 1 shows that the heat of reaction for this peak increases systematically with clay content. This is further illustrated in Figure 8, where it can be confirmed that the heat of

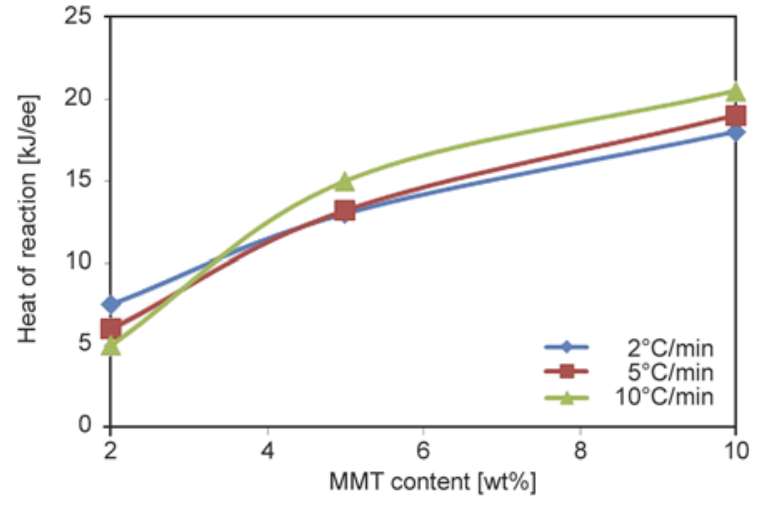

Figure 8. Dependence on MMT content of the heat of reaction corresponding to the $2^{\text {nd }}$ peak for different heating rates: $2^{\circ} \mathrm{C} / \mathrm{min}$, blue rhombus; $5^{\circ} \mathrm{C} / \mathrm{min}$, red squares; $10^{\circ} \mathrm{C} / \mathrm{min}$, green triangles.

reaction is essentially independent of heating rate. The presence of MMT therefore clearly enhances this $2^{\text {nd }}$ reaction. Examination of Figure 7 shows that the $2^{\text {nd }}$ reaction begins at about the temperature of the maximum of the $1^{\text {st }}$ peak, and since the intragallery reaction has therefore already largely occurred simultaneously with the cross-linking reaction in the $1^{\text {st }}$ peak, we attribute the $2^{\text {nd }}$ peak to an extragallery epoxy homopolymerisation reaction catalysed by the organically modified MMT.

The $3^{\text {rd }}$ peak shows a dramatic decrease in the heat of reaction simply as a result of the presence of clay, with no significant or systematic dependence on the clay content. This peak is assigned to the extragallery epoxy homopolymerisation reaction, initiated by tertiary amines. The strong reduction in the heat of reaction corresponding to this peak when the clay is added may be attributed mainly to the epoxy homopolymerisation that is now taking place within the clay galleries, leaving fewer epoxy groups to react in the extra-gallery regions.

\subsection{Kinetic analysis of the TGAP/DDS/MMT system}

The separation of the composite peak into the three peaks corresponding to the reactions discussed above allows also the determination of, amongst other things, their individual activation energies. By applying the Kissinger method, the activation energy for each of these reactions has been found, and the results are given in Table 2 for comparison with the Kissinger values of the activation energy obtained for the composite curves without deconvolution.

Considering first the TGAP/DDS system without clay, for which the non-isothermal cure curves at 2 , 
Table 2. Kinetic parameters for non-isothermal cure of the TGAP/DDS/MMT system

\begin{tabular}{|l|c|c|c|c|}
\hline \multirow{2}{*}{ MMT content } & $\mathbf{0}$ & $\mathbf{2}$ & $\mathbf{5}$ & $\mathbf{1 0}$ \\
\cline { 2 - 5 } & \multicolumn{5}{|c|}{ [wt\%] } \\
\hline \multicolumn{5}{|c|}{$\mathbf{1}^{\text {st }}$ peak: } \\
\hline$E[\mathrm{~kJ} / \mathrm{mol}]$ & 74 & 77 & 72 & 80 \\
\hline$A\left[\mathrm{~s}^{-1}\right]$ & $4.0 \cdot 10^{5}$ & $1.7 \cdot 10^{6}$ & $6.4 \cdot 10^{5}$ & $4.4 \cdot 10^{6}$ \\
\hline$m$ & 0.5 & 0.4 & 0.5 & 0.2 \\
\hline$n$ & 1.6 & 1.6 & 1.5 & 1.7 \\
\hline$m+n$ & 2.1 & 2.0 & 2.0 & 1.9 \\
\hline \multicolumn{5}{|c|}{$\mathbf{2}^{\text {nd }}$ peak: } \\
\hline \multicolumn{5}{|c|}{ extra-gallery homopolymerisation, catalysed by MMT } \\
\hline$E[\mathrm{~kJ} /$ mol $]$ & - & 93 & 79 & 62 \\
\hline \multicolumn{5}{|c|}{$\mathbf{3}^{\text {rd }}$ peak: } \\
extra-gallery homopolymerisation, catalysed by tertiary amine \\
\hline$E[\mathrm{~kJ} / \mathrm{mol}]$ & 82 & 106 & 97 & 97 \\
\hline
\end{tabular}

5 and $10 \mathrm{~K} / \mathrm{min}$ are shown in Figure 2, the Kissinger activation energy corresponding to these three heating rates is found as $60.1 \mathrm{~kJ} / \mathrm{mol}$. This is somewhat larger than the value of $50.9 \mathrm{~kJ} / \mathrm{mol}$ quoted by Varley et al. [34] for the same TGAP/DDS system, but the explanation for this apparent discrepancy lies in the range of heating rates and in the averaging process associated with the Kissinger method. Varley et al. [34] use a range of heating rates from 2 to $30 \mathrm{~K} / \mathrm{min}$ for their evaluation of the activation energy, whereas our value of $60.1 \mathrm{~kJ} / \mathrm{mol}$ is obtained for a more limited range, covering the slower heating rates. When we extend the range of heating rates to include also 20 and $30 \mathrm{~K} / \mathrm{min}$, the average activation energy is found to be $50.4 \mathrm{~kJ} / \mathrm{mol}$, in very close agreement with Varley et al. [34]. The dependence of $\ln \left(\beta / T_{\mathrm{p}}^{2}\right)$ on the reciprocal of $T_{\mathrm{p}}$ is clearly not linear over the whole range of heating rates, and the reason for this is that the overall cure curves, such as those shown in Figure 2 for the TGAP/DDS system, consist of more than a single reaction, each reaction having a different activation energy. It is therefore not very meaningful to evaluate the Kissinger activation energy, as the value will depend on which reaction is predominant in determining the peak temperature according to the range of heating rates used.

The same considerations apply also to the TGAP/ DDS/MMT system, for which the non-isothermal cure curves for the $5 \mathrm{wt} \%$ clay content are shown in Figure 6 , for heating rates of 2,5 and $10 \mathrm{~K} / \mathrm{min}$. Using this range of heating rates, the Kissinger activation energy is found as $63.8 \mathrm{~kJ} / \mathrm{mol}$, whereas the inclusion of the higher heating rates of 20 and $30 \mathrm{~K} / \mathrm{min}$ gives a value of $56.5 \mathrm{~kJ} / \mathrm{mol}$. In general, the observed reduction in the Kissinger activation energy as the range of heating rates is extended to higher values is consistent with the activation energies found for the deconvoluted peaks and shown in Table 2: the activation energies for the $2^{\text {nd }}$ and $3^{\text {rd }}$ peaks are higher than those for the $1^{\text {st }}$ peak; at lower heating rates, where the different reactions overlap in the approximate range of their peak temperatures, the $2^{\text {nd }}$ and $3^{\text {rd }}$ reactions significantly influence the composite peak temperature; on the other hand, at higher heating rates the $2^{\text {nd }}$ and $3^{\text {rd }}$ peaks are more separated from the $1^{\text {st }}$ peak, because their activation energies are higher, and hence the composite peak temperature becomes associated principally with the $1^{\text {st }}$ peak, and hence with a lower activation energy.

Considering in more detail the activation energies for the various peaks indicated in Table 2, we note the following characteristics. The significantly higher activation energies for both the $2^{\text {nd }}$ and $3^{\text {rd }}$ peaks in comparison with that for the $1^{\text {st }}$ peak, is consistent with their assignation as homopolymerisation reactions. The $3^{\text {rd }}$ peak in particular has a very high activation energy, which would be anticipated for a thermally catalysed homopolymerisation reaction. For the $2^{\text {nd }}$ peak, attributed here to an extra-gallery homopolymerisation reaction catalysed by the onium ion of the organically modified MMT, the activation energy is somewhat lower than that for the $3^{\text {rd }}$ peak, and there is a noticeable decrease in the activation energy with increasing MMT content, consistent with a catalytic effect of the MMT, as has been noted before $[22,23]$.

After determining the activation energies, the kinetic exponents $m$ and $n$ in Equation (3) for the $1^{\text {st }}$ peak, which is a combination of the epoxy-amine crosslinking reaction and the intra-gallery homopolymerisation reaction, can be evaluated by Malek's method [32] using the TAS software. The average values for these parameters are included in Table 2. Typically, $m$ must be less than 1 and the sum of the reaction orders $(m+n)$ should be around 2 or 3, conditions which are met by these results. It is interesting, however, to compare these values with those found for the isothermal cure of both the same TGAP/DDS/MMT system and the TGAP/DDS system without any clay [23]. For the former system, containing $5 \mathrm{wt} \%$ MMT, for which the epoxy-amine cross-linking reaction could be deconvoluted from the rapid intra-gallery homopolymerisation reaction, there was some variation of the values of the 
parameters $m$ and $n$ depending on the isothermal cure temperature, the average values being $m=$ $0.6 \pm 0.2$ and $n=2.1 \pm 0.4$, while for the latter system, without clay, the values were $m=0.8$ and $n=2.6$ approximately. The isothermal cure of the TGAP/ DDS system is therefore seen to be highly autocatalytic, which can be understood in terms of the production of secondary amines by the reaction of the epoxy with primary amines. In the TGAP/DDS/ MMT system, on the other hand, the isothermal cross-linking reaction appears to be less autocatalytic, which we might infer to be an effect of the presence of the clay. For the non-isothermal cure of this TGAP/DDS/MMT system, for which the results are presented in Table 2, the further reduction in the values of $m$ and $n$ for the $1^{\text {st }}$ reaction, which is attributed to the combination of the epoxy-amine crosslinking reaction in the presence of clay and the intragallery homopolymerisation reaction, is consistent with this scenario.

\subsection{Nanostructural analysis}

An improvement in the degree of exfoliation of the nanostructure of the cured nanocomposite can be achieved by promoting the intra-gallery homopolymerisation reaction such that it occurs before the extra-gallery cross-linking reaction. This was shown clearly in earlier work with this same TGAP/DDS/ MMT system [22, 23], where for isothermal cure the intra-gallery reaction at least partially preceded the epoxy-amine cross-linking reaction. In contrast, for the isothermal cure of PLS nanocomposites based upon DGEBA epoxy, the occurrence of the intragallery homopolymerisation reaction after, rather than before, the cross-linking reaction results in a very poorly exfoliated nanocomposite [17]. During the non-isothermal cure of the system studied here, a composite peak appears for which the $1^{\text {st }}$ peak represents the contribution from the combination of the TGAP-amine cross-linking reaction and the intragallery homopolymerisation reaction catalysed by the onium ion of the modified MMT, both reactions occurring simultaneously. As this composite peak cannot be deconvoluted into the separate contributions of the epoxy-amine reaction and the homopolymerisation reaction, it is not clear from the reaction kinetics how the nanostructure might develop. Accordingly, nanostructural characterisation is required in order to identify whether or not a high degree of exfoliation is obtained for this system when it is cured non-isothermally. We recall that, from a consideration of the effect of the clay content on the heat of reaction for the 1st peak, shown in Table 1, it was concluded that the greatest amount of intragallery reaction occurs for the sample containing $10 \mathrm{wt} \%$ MMT. Consequently, we examine by SAXS and TEM the nanostructure of non-isothermally cured samples containing $10 \mathrm{wt} \%$ MMT. The SAXS diffractogram is shown in Figure 9, which should be compared with the scattering observed for the organically modified MMT alone, which gives a marked peak at an angle of $4.2^{\circ}$ corresponding to a d-spacing of $2.1 \mathrm{~nm}[16]$, and for the same nanocomposite systems cured isothermally [23], for which the diffractograms were qualitatively identical to that shown in Figure 9 for the non-isothermally cured sample. In Figure 9 there remains no evidence of the strong scattering of the MMT; instead it can be seen that, after the initial rapid fall corresponding to the background scattering, there are no scattering peaks evident within the range of angles covered here, implying that there is no regular layer stacking with a d-spacing less than about $8 \mathrm{~nm}$. The same observation, namely the lack of scattering peaks in the low angle range, was also made for the nanocomposite systems with 2 and $5 \mathrm{wt} \%$ clay contents; the diffractograms for these samples were qualitatively identical to that in Figure 9, the only difference being in the intensity, which depends on the clay content. These non-isothermally cured samples would therefore appear to be exfoliated, but this conclusion must be corroborated by TEM observations.

The TEM micrographs are shown in Figure 10, at various magnifications. The lowest magnification can be seen in Figures 10a and 10b, where portions

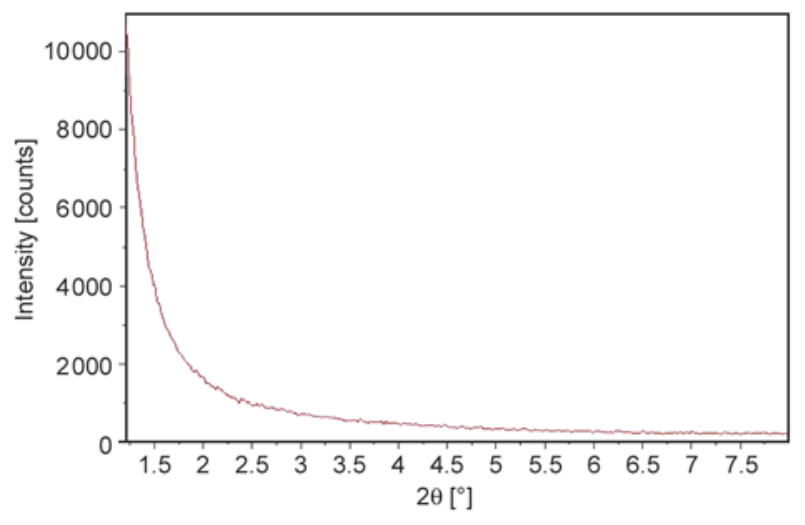

Figure 9. SAXS diffractogram for the TGAP/DDS/MMT $(10 \mathrm{wt} \%)$ sample cured non-isothermally at $10^{\circ} \mathrm{C} / \mathrm{min}$ 


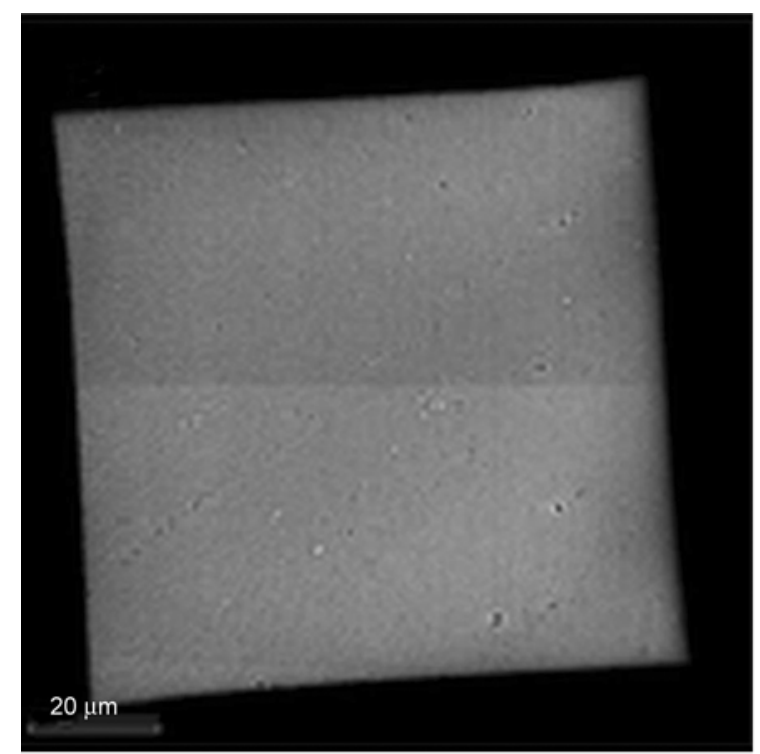

a)

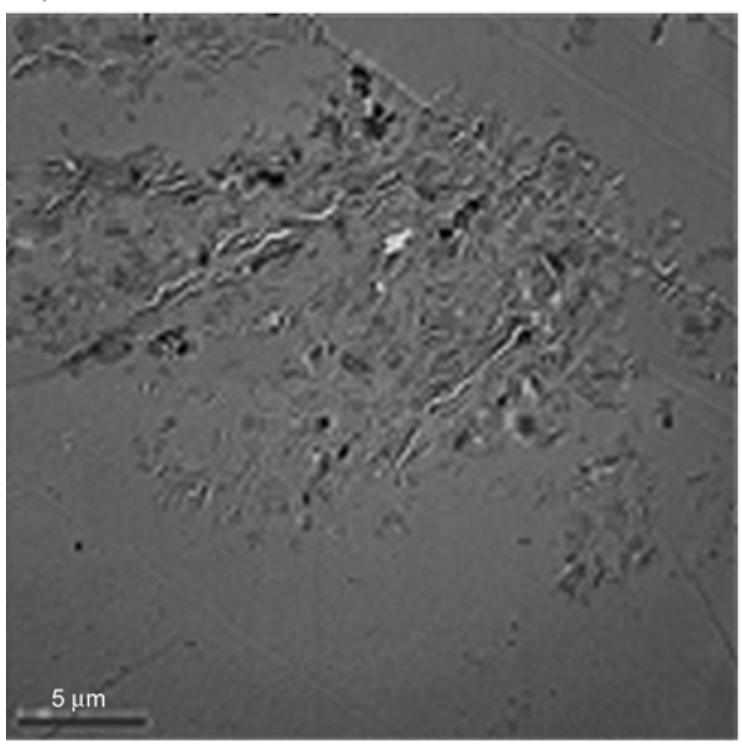

c)

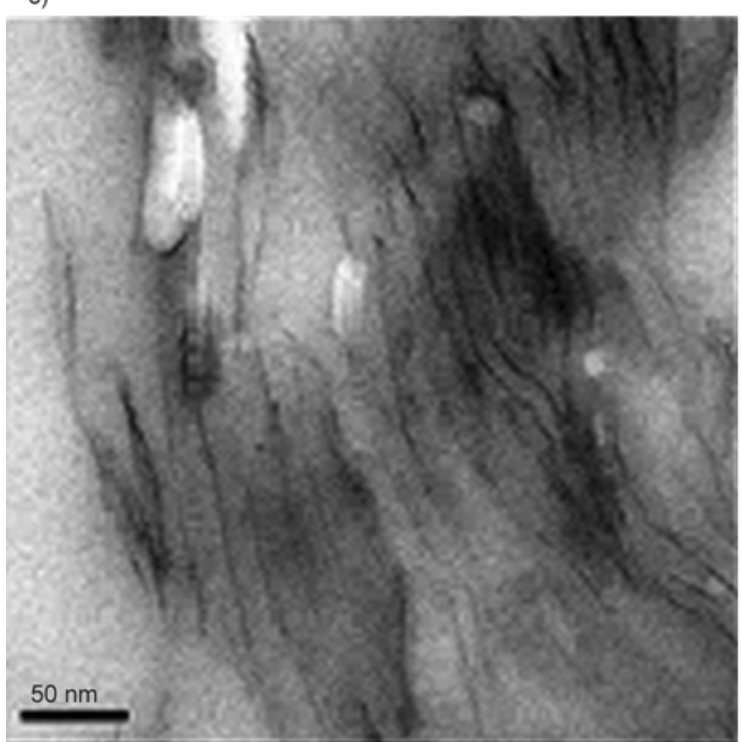

e)

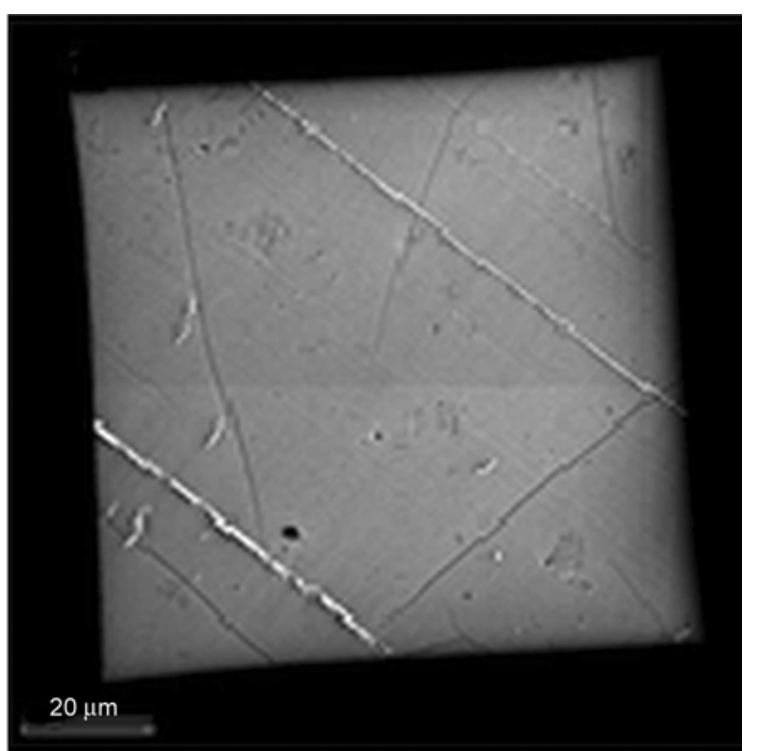

b)

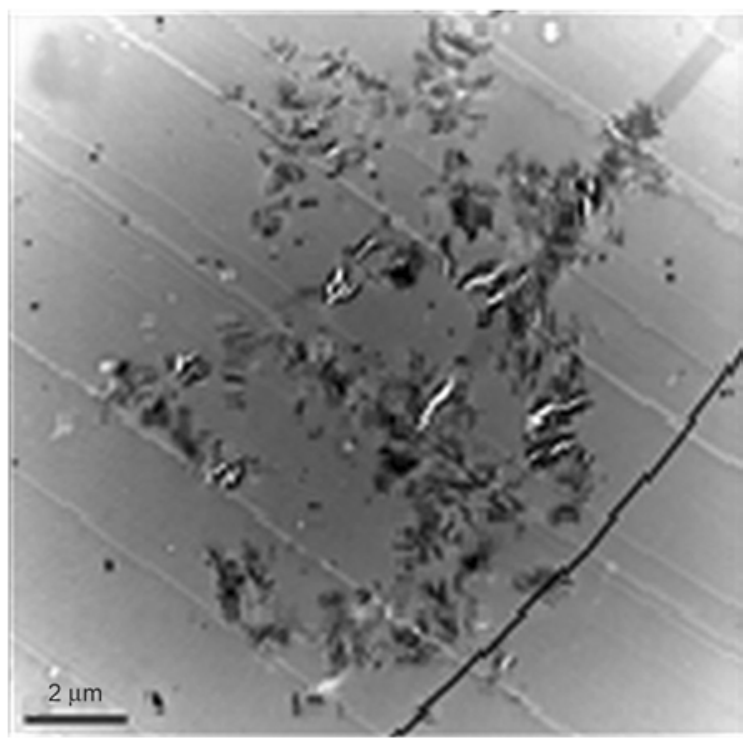

d)

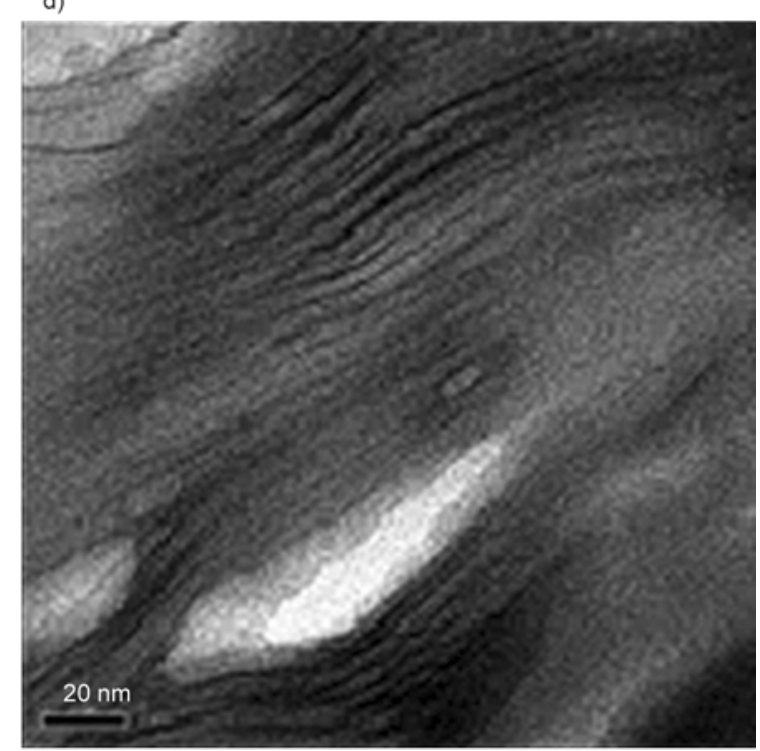

f)

Figure 10. TEM images for the TGAP/DDS/MMT (10 wt\%) system cured non-isothermally at $10^{\circ} \mathrm{C} / \mathrm{min}$. The scale bars are: (a) $20 \mu \mathrm{m}$; (b) $20 \mu \mathrm{m}$; (c) $5 \mu \mathrm{m}$; (d) $2 \mu \mathrm{m}$; (e) $50 \mathrm{~nm}$; (f) $20 \mathrm{~nm}$. 
of two different ultra-microtomed sections of the same sample are each framed by a single grid of the support; these images, which are typical of the whole sample, indicate that in some areas there are no clay agglomerations visible (Figure 10a), while in other areas a number of clay agglomerations can be seen (Figure 10b), the largest here being between 5 and $10 \mu \mathrm{m}$ in size, but in other areas some agglomerations may be as large as 20 to $25 \mu \mathrm{m}$ in size. At higher magnifications (Figures 10c and 10d), typical agglomerations are seen to be composed of 'islands' with a relatively high density of clay layers, these 'islands' being separated and surrounded by the epoxy matrix, presumably containing well distributed and exfoliated clay layers. Any one of these 'islands', at even higher magnification, such as that shown in Figure 10e, can be seen to consist of a number of clay layers separated by distances of, typically, between 10 and $20 \mathrm{~nm}$, which represents a significant degree of exfoliation. Nevertheless, there are regions in which some clay layers retain their original layer stacking, albeit with an increased layer separation. Figure $10 \mathrm{f}$ shows one such region, where many clay layers can be seen in register, with a spacing of only 4 to $5 \mathrm{~nm}$ between them; this region clearly does not represent a well exfoliated nanostructure. Nevertheless, the overall nanostructure evident from these TEM micrographs is similar to that observed for the isothermal cure of the same nanocomposite system [23]. We infer from this that the combination of the epoxy-amine cross-linking reaction and the intra-gallery homopolymerisation reaction which constitutes the 1st peak in the non-isothermal cure of the TGAP/DDS/MMT system retains the relationship between these two reactions that was evident in the isothermal cure, namely that the intra-gallery reaction is not significantly inhibited by the epoxyamine cross-linking reaction in the extra-gallery regions.

Although only the sample with $10 \mathrm{wt} \%$ clay content has been studied here by TEM, as it was expected to give the greatest amount of intra-gallery reaction, we believe that the similarity of nanostructure evidenced by TEM between isothermally and non-isothermally cured samples could be extended also to the lower clay contents of 2 and $5 \mathrm{wt} \%$. We base this on the SAXS results, which were obtained for all three clay contents, and which show that in all cases there is no indication of any diffraction peak in the low angle range, as well as on the following argument.
In many ways, the $10 \mathrm{wt} \%$ sample can be considered to be the most 'problematic', and hence a good degree of exfoliation would be anticipated for the 2 and $5 \mathrm{wt} \%$ samples if it is, as shown in Figures 9 and 10 , present in the $10 \mathrm{wt} \%$ sample. The reason for this is that the initial dispersion of the clay in the epoxy is an important factor in the nanostructure development, and this dispersion improves as the clay content decreases. If there are significant agglomerations present, then the epoxy cannot penetrate to the clay in the heart of these agglomerations, and hence the intra-gallery reaction will not occur there. Figure 10 shows that some agglomerations clearly remain, but they are not nearly as large as in some other epoxy-clay systems, and their effect is apparently not to inhibit the intra-gallery homopolymerisation reaction, inasmuch as Table 1 shows that the heat of reaction decreases significantly for the $10 \mathrm{wt} \%$ sample (as a result of homopolymerisation having a lower heat of reaction) while Figure 9 shows that there is no layer stacking that would occur if the epoxy could not enter the galleries. It is concluded from this that if the relative rates of intraand extra-gallery reactions for the $10 \mathrm{wt} \%$ sample are such that the latter does not inhibit the former, then the same would be true, and even more so, for the lower clay contents of 2 and $5 \mathrm{wt} \%$.

\section{Conclusions}

In the non-isothermal cure of the TGAP/DDS/MMT system, the composite curve can be deconvoluted into three separate peaks corresponding to three different reactions, in contrast to isothermal cure for which there are only two contributions. These three peaks are: (i) a combination of the epoxy-amine cross-linking reaction and an intra-gallery homopolymerisation reaction; (ii) an extra-gallery homopolymerisation reaction which is catalysed by the organically modified MMT; and (iii) another extra-gallery homopolymerisation reaction, which is catalysed by tertiary amines. But the important distinction between the isothermal and non-isothermal cure kinetics is that, for non-isothermal cure, the intragallery reaction occurs concurrently with the epoxyamine cross-linking reaction taking place in the extra-gallery regions, in contrast to isothermal cure for which the epoxy-amine cross-linking reaction takes place after the intra-gallery reaction. This distinction between the two cure schedules has been related to differences in the kinetics of isothermal 
and non-isothermal cure. Despite these differences between the isothermal and non-isothermal cure kinetics, however, it appears that the final nanostructure resulting from the two cure schedules is very similar when examined by SAXS and TEM. Just as for isothermal cure, no scattering peak can be detected by SAXS for the non-isothermally cured nanocomposites. Nevertheless, the TEM images show, similarly to the isothermally cured samples, the existence of some clay agglomerations which consist of a number of clay layers with a d-spacing typically in the range from 10 to $20 \mathrm{~nm}$. Hence, the final nanostructure presents a good quality of exfoliation, similar to that observed previously for samples which were cured isothermally. This implies that the intra-gallery homopolymerisation reaction, which is a necessary stage in the exfoliation process, is not significantly inhibited by the epoxy-amine cross-linking reaction occurring simultaneously in the extragallery regions.

\section{Acknowledgements}

The authors are grateful to Huntsman Corporation for the epoxy resin and curing agent and to Nanocor Inc. for the organically modified clay. This work was supported financially by MINECO Projects MAT2011-27039-C03 and MAT2014-53706-C3-3-R. F.S. is grateful for a grant from the Agència de Gestió d'Ajuts Universitaris i de Recerca (AGAUR), FI-DGR 2011.

\section{References}

[1] LeBaron P. C., Wang Z., Pinnavaia T. J.: Polymer-layered silicate nanocomposites: An overview. Applied Clay Science, 15, 11-29 (1999).

DOI: 10.1016/S0169-1317(99)00017-4

[2] Alexandre M., Dubois P.: Polymer-layered silicate nanocomposites: Preparation, properties and uses of a new class of materials. Materials Science and Engineering R: Reports, 28, 1-63 (2000).

DOI: $10.1016 / \mathrm{S} 0927-796 \mathrm{X}(00) 00012-7$

[3] Ray S. S., Okamoto M.: Polymer/layered silicate nanocomposites: A review from preparation to processing. Progress in Polymer Science, 28, 1539-1641 (2003). DOI: $10.1016 /$ j.progpolymsci.2003.08.002

[4] Becker O., Simon G. P., Dusek K.: Epoxy layered silicate nanocomposites. Advances in Polymer Science, 179, 29-82 (2005). DOI: $10.1007 / \mathrm{b} 107204$

[5] Karak N.: Polymer (epoxy) clay nanocomposites. Journal of Polymer Materials, 23, 1-20 (2006).
[6] Hussain F., Hojjati M., Okamoto M., Gorga R. E.: Review article: Polymer-matrix nanocomposites, processing, manufacturing, and application: An overview. Journal of Composite Materials, 40, 1511-1575 (2006). DOI: $\underline{10.1177 / 0021998306067321}$

[7] Pavlidou S., Papaspyrides C. D.: A review on polymer-layered silicate nanocomposites. Progress in Polymer Science, 33, 1119-1198 (2008).

DOI: $10.1016 /$ j.progpolymsci.2008.07.008

[8] Wang M. S., Pinnavaia T. J.: Clay-polymer nanocomposites formed from acidic derivatives of montmorillonite and an epoxy resin. Chemistry of Materials, 6 , 468-474 (1994).

DOI: $10.1021 / \mathrm{cm} 00040 \mathrm{a} 022$

[9] Butzloff P., D’Souza N. A., Golden T. D., Garrett D.: Epoxy + montmorillonite nanocomposite: Effect of composition on reaction kinetics. Polymer Engineering and Science, 41, 1794-1802 (2001).

DOI: $10.1002 /$ pen. 10876

[10] Kornmann X., Lindberg H., Berglund L. A.: Synthesis of epoxy-clay nanocomposites. Influence of the nature of the curing agent on structure. Polymer, 42, 44934499 (2001).

DOI: 10.1016/S0032-3861(00)00801-6

[11] Xu W., Bao S., Shen S., Wang W., Hang G., He P.: Differential scanning calorimetry study on the curing behaviour of epoxy resin/diethylenetriamine/organic montmorillonite nanocomposite. Journal of Polymer Science Part B: Polymer Physics, 41, 378-386 (2003). DOI: $10.1002 /$ polb.10365

[12] Becker O., Simon G. P., Varley R. J., Halley P. J.: Layered silicate nanocomposites based on various highfunctionality epoxy resins: The influence of an organoclay on resin cure. Polymer Engineering and Science, 43, 850-862 (2003).

DOI: $10.1002 /$ pen. 10070

[13] Chen C., Curliss D.: Preparation, characterization, and nanostructural evolution of epoxy nanocomposites. Journal of Applied Polymer Science, 90, 2276-2287 (2003).

DOI: 10.1002/app.12901

[14] Ton-That M-T., Ngo T-D., Ding P., Fang G., Cole K. C., Hoa S. V.: Epoxy nanocomposites: Analysis and kinetics of cure. Polymer Engineering and Science, 44, 1132-1141 (2004).

DOI: $10.1002 /$ pen.20106

[15] Ivankovic M., Brnardic I., Ivankovic H., Mencer H. J.: DSC study of the cure kinetics during nanocomposite formation: Epoxy/poly(oxypropylene) diamine/organically modified montmorillonite system. Journal of Applied Polymer Science, 99, 550-557 (2006). DOI: $10.1002 /$ app. 22488

[16] Román F., Montserrat S., Hutchinson J. M.: On the effect of montmorillonite in the curing reaction of epoxy nanocomposites. Journal of Thermal Analysis and Calorimetry, 87, 113-118 (2007).

DOI: $10.1007 / \mathrm{s} 10973-006-7830-9$ 
[17] Montserrat S., Román F., Hutchinson J. M., Campos L.: Analysis of the cure of epoxy based layered silicate nanocomposites: Reaction kinetics and nanostructure development. Journal of Applied Polymer Science, 108, 923-938 (2008).

DOI: 10.1002/app. 27297

[18] Pustkova P., Hutchinson J. M., Román F., Montserrat S.: Homopolymerization effects in polymer layered silicate nanocomposites based upon epoxy resin: Implications for exfoliation. Journal of Applied Polymer Science, 114, 1040-1047 (2009).

DOI: 10.1002/app.30697

[19] Xu Y., Peng H., Wang X., Su S.: Comparative study of different polymerically-modified clays on curing reaction and thermal properties of epoxy resin. Thermochimica Acta, 516, 13-18 (2011).

DOI: $10.1016 /$ j.tca.2011.01.004

[20] Román F., Calventus Y., Colomer P., Hutchinson J. M.: Identification of nanostructural development in epoxy polymer layered silicate nanocomposites from the interpretation of differential scanning calorimetry and dielectric spectroscopy. Thermochimica Acta, 541, 76-85 (2012).

DOI: $10.1016 /$ j.tca.2012.05.001

[21] Becker O., Cheng Y-B., Varley R. J., Simon G. P.: Layered silicate nanocomposites based on various highfunctionality epoxy resins: The influence of cure temperature on morphology, mechanical properties, and free volume. Macromolecules, 36, 1616-1625 (2003).

DOI: $10.1021 / \mathrm{ma} 0213448$

[22] Hutchinson J. M., Shiravand F., Calventus Y.: Intraand extra-gallery reactions in tri-functional epoxy polymer layered silicate nanocomposites. Journal of Applied Polymer Science, 128, 2961-2970 (2013).

DOI: $10.1002 / a p p .38452$

[23] Shiravand F., Hutchinson J. M., Calventus Y.: Influence of the isothermal cure temperature on the nanostructure and thermal properties of an epoxy layered silicate nanocomposite. Polymer Engineering and Science, 54, 51-58 (2014).

DOI: $10.1002 /$ pen. 23540

[24] Hutchinson J. M., Shiravand F., Calventus Y., Fraga I.: Isothermal and non-isothermal cure of a tri-functional epoxy resin (TGAP): A stochastic TMDSC study. Thermochimica Acta, 529, 14-21 (2012).

DOI: $10.1016 /$ j.tca.2011.11.008

[25] Vyazovkin S., Burnham A. K., Criado J. M., PérezMaqueda L. A., Popescu C., Sbirrazzuoli N.: ICTAC Kinetics Committee recommendations for performing kinetic computations on thermal analysis data. Thermochimica Acta, 520, 1-19 (2011). DOI: $10.1016 / j . t c a .2011 .03 .034$

[26] Starink M. J.: The determination of activation energy from linear heating rate experiments: A comparison of the accuracy of isoconversion methods. Thermochimica Acta, 404, 163- 176 (2003). DOI: $\underline{10.1016 / \mathrm{S} 0040-6031(03) 00144-8}$
[27] Ozawa T.: A new method of analyzing thermogravimetric data. Bulletin of the Chemical Society of Japan, 38, 1881-1886 (1965).

DOI: $10.1246 / \mathrm{bcsj} .38 .1881$

[28] Vyazovkin S.: Evaluation of activation energy of thermally stimulated solid-state reactions under arbitrary variation of temperature. Journal of Computational Chemistry, 18, 393-402 (1997).

DOI: $10.1002 /($ SICI)1096-987X(199702)18:3<393::

$$
\text { AID-JCC9>3.0.CO;2-P }
$$

[29] Vyazovkin S.: Modification of the integral isoconversional method to account for variation in the activation energy. Journal of Computational Chemistry, 22, 178183 (2001).

DOI: $10.1002 / 1096-987 X(20010130) 22: 2<178:: A I D-$ JCC5>3.0.CO;2-\#

[30] Kissinger H. E.: Variation of peak temperature with heating rate in differential thermal analysis. Journal of Research of the National Bureau of Standards, 57, 217-221 (1956).

[31] Kissinger H. E.: Reaction kinetics in differential thermal analysis. Analytical Chemistry, 29, 1702-1706 (1957). DOI: $10.1021 / \mathrm{ac} 60131 \mathrm{a} 045$

[32] Málek J.: The kinetic analysis of non-isothermal data. Thermochimica Acta, 200, 257-269 (1992). DOI: 10.1016/0040-6031(92)85118-F

[33] Frigione M., Calò E.: Influence of an hyperbranched aliphatic polyester on the cure kinetic of a trifunctional epoxy resin. Journal of Applied Polymer Science, 107, 1744-1758 (2008).

DOI: $10.1002 / a p p .27277$

[34] Varley R. J., Hodgkin J. H., Hawthorne D. G., Simon G. P.: Toughening of a trifunctional epoxy system. II. Thermal characterization of epoxy/amine cure. Journal of Applied Polymer Science, 60, 2251-2263 (1996). DOI: 10.1002/(SICI)1097-4628(19960620)60:12<2251 $\because$ AID-APP24>3.0.CO;2-8

[35] Smith I. T.: The mechanism of the crosslinking of epoxide resins by amines. Polymer, 2, 95-108 (1961). DOI: 10.1016/0032-3861(61)90010-6

[36] Ryan M. E., Dutta A.: Kinetics of epoxy cure: A rapid technique for kinetic parameter estimation. Polymer, 20, 203-206 (1979).

DOI: 10.1016/0032-3861(79)90222-2

[37] Hutchinson J. M., Montserrat S., Román F.: Nanostructure development and cure kinetics in epoxy-based PLS nanocomposites. Journal of Nanostructured Polymers and Nanocomposites, 4, 13-20 (2008).

[38] Klute C. H., Viehmann W.: Heat of polymerization of phenyl glycidyl ether and of an epoxy resin. Journal of Applied Polymer Science, 5, 86-95 (1961). DOI: 10.1002/app.1961.070051313

[39] Dell'Erba I. E., Williams R. J. J.: Homopolymerization of epoxy monomers initiated by 4-(dimethylamino) pyridine. Polymer Engineering and Science, 46, 351359 (2006).

DOI: $10.1002 /$ pen.20468 